Marta Łabuś-Centek', Anna Adamczyk', Agnieszka Jagielska', Beata Brożek', Michał Graczyk', Philip Larkin², Małgorzata Krajnik'

${ }^{1}$ Ludwik Rydygier Collegium Medicum in Bydgoszcz, Nicolaus Copernicus University in Toruń, Bydgoszcz, Poland

${ }^{2}$ Chaire Kristian Gerhard Jebsen de soins palliatifs infirmiers, IUFRS/CHUV, University of Lausanne, Switzerland

\title{
Application of dignity therapy in an advanced cancer patient — wider therapeutic implications
}

\section{Abstract}

Aim: Dignity therapy is a short-term, individualized, patient-focused form of therapy reducing stress and helping both the patient and his family appreciate the end-of-life situation. The present study describes the impact of dignity therapy on an advanced cancer patient within a Polish hospital setting.

Methods: MH. Chochinov's dignity therapy protocol was applied. A session was conducted during which an interview with the patient was recorded; subsequently subjected to a statistical analysis. The competent judges' approach was used to effectively preclude subjective interpretation of the patient's statement by an investigator. The judges' appraisal was then checked for concordance (W Kendall). The patient was also asked to complete a survey questionnaire designed to assess the therapeutic effectiveness of dignity therapy in the intervention.

Results: The patient indicated that family epitomized the most crucial values. He also highlighted other issues, i.e. his work and life's passion - playing the drums. The survey questionnaire indicated that by far the greatest benefit consisted in an overall improvement of his mental well-being (4.67). Benefits for the family followed (4), including his hope for recovering family ties (4). An unexpected therapeutic effect consisted in re-establishing a broken relationship with his daughters.

Conclusions: Dignity therapy proved effective not only as a method of enhancing the patient's own sense of dignity in the face of impending death but also tangibly instrumental in overcoming a dramatic communication break within a family.

Palliat Med Pract 2018; 12, 4: 218-223

Key words: dignity therapy, palliative care, advanced cancer

Non omnis moriar multaque pars mei vitabit Libitinam [1]. I shall not wholly die and a greater part of me will evade Libitina [Goddess of Death]

\section{Introduction}

Dignity therapy is a short-term, individualized therapy, focused on the patient and his family, aimed at relieving stress, and facilitating a conscious experience of the end-of-life in the circumstances of impending death [2]. Reflecting upon the most significant and memorable events in the patient's life, its purpose consists also in sharing these events and reflections on with the family. The World Health Organization

\footnotetext{
Adres do korespondencji:

Marta Łabuś-Centek

Ludwik Rydygier Collegium Medicum in Bydgoszcz,

Nicolaus Copernicus University in Toruń,

ul. Jagiellońska 13-15, 85-067 Bydgoszcz

e-mail: martalabus@poczta.onet.pl
} 
highlights the role of palliative care not only in the treatment of pain and other somatic symptoms, but also in addressing various psychosocial and spiritual issues [3]. Research by Chochinov et al. determined that patients who attended a dignity therapy session confirmed its effectiveness of this approach, noting appreciable improvement in overall quality of life, and a boost to an individual sense of dignity. The patients' families also gained benefits from this experience [2].

\section{Case report}

A single patient, a 62-year-old man diagnosed with advanced rectal cancer, homeless and with social problems, out of touch with his family, was selected from the Department of Palliative Care to attend a dignity therapy session. During his initial 5-month stay at the Department, the patient was simultaneously put on palliative chemotherapy. In the meantime, the patient suffered left-sided epididymitis, a decompression of the perianal abscess located on the left buttock was carried out, and attendant surgical drainage was fitted in the Surgery Clinic. Due to a significant deterioration in the patient's general condition chemotherapy was discontinued. Prior to the application of dignity therapy, the patient was on the following medications: morphine, estazolam (overnight only), tamsulosin, and gabapentin. Additionally, etamsylate, paracetamol, metamizole, tranexamic acid and midazolam were given p. r. $\mathrm{n}$.

The patient had a good relationship with a psychologist, and attended the relaxation classes. He would happily chat with a psychologist almost every day and emphasized that he received a lot of help from her. He rarely exhibited negative emotions, refrained from crying, even though he often touched upon a variety of personally difficult and painful subjects. When well, he was pro-active, fostering positive relationships with people outside his own ward. He was aware of his illness and adverse prognosis and often discussed these issues with a psychologist. A strong and well-established relationship with the therapist was deemed an essential factor in discussing the end-of-life issues with the patient [4].

An important matter in terms of the patient's physical and mental well-being was the neoplastic lesion on his buttock. He closely observed the progression of the disease in the appearance of the lesion, and a disagreeable odour emanating from the affected area, often looking closely at it in the mirror. This made him think of his progressively deteriorating condition and impending death. Neoplastic lesions remaining on the outside of the body are often deemed an extra emotional problem for the patients to cope with [5]. The treatment of his cancer ulceration was sympto- matic. Due to the actual location of the lesion itself, it was dressed through rinsing with liquid octenidine twice a day and the application of the octenidine gel plus a secondary dressing - twice a day. Occasional slight bleeding after perforation of the neoplastic lesion infiltrating upon the buttock did not require any additional treatment. Nursing assessment and observation was included (close observation of the neoplastic lesion, body temperature control, assessment of pain intensity). All of those activities were important to a patient, in that he felt that medical staff care about him. He trusted all employees very much and was grateful for the help. He repeatedly emphasized this fact.

\section{Methods}

The Bioethical Commission of the Nicolaus Copernicus University, Torun, Poland approved to access the patient's data for publication purposes (Ref. no KB184/2018).

By way of preparation, three days prior to the planned therapeutic session, the patient was furnished with nine questions (Table 1) developed in line with the Chochinov approach [2]. Prior to the therapeutic session, the patient gave consent to attend the procedure, as well as to have any of the materials used for scientific, didactic and publication purposes. Then, an interview with the patient was held in line with the above-referenced protocol and recorded. In line with the patient's wish, it was sent to his daughter.

The patient's responses were subjected to content analysis and preliminary qualitative analysis, summarized in sections. Three independent 'competent judges' (persons totally unknown to the patient, professionally unrelated to the health care domain) were appointed and asked to watch the recording and identify the aspects of greatest significance within the patient's respective responses, so to verify whether the patient's message was clear and unambiguous.

A list of responses that the psychologist conducting the session and the judges deemed most significant was drafted. The judges then individually rated all the sub-points reflecting the significance of particular issues raised by the patient. The judges' concordance was checked with the aid of Kendall's $W$ coefficient of concordance (Table 2).

On the second day, the patient completed a locally devised questionnaire meant to assess the actual effectiveness of the therapy (Table 3). Responses were divided into three categories, i.e. benefits for one's mental well-being, benefits for the family, and hope for an improvement in the relationships with the family, and the arithmetic mean was calculated (Table 4). 
Table 1. The protocol of dignity therapy questions, based on HM. Chochinov [2]

\section{The protocol of dignity therapy questions}

1. Please tell me your life story, especially about what you remember best, or consider of great significance? When did you feel the greatest appetite for life?

2. Is there anything specific about yourself that you would like your family to know, or anything special that you would like your family to cherish?

3. What was the most important role that you played in your own life, and why was it so important to you? What did it you manage to achieve through it?

4. What was your greatest lifetime achievement, what did you feel the most proud of?

5. Is there anything that you would like to tell your relatives about, or highlight to them once again?

6. What do you dream about for your relatives?

7. What have you learned about life at large and would now like to get across to others? What sort of advice would you like to offer to your loved ones?

8. Are there any messages or instructions that you would like to get across to your family to help them prepare better for the future?

9. Are there anything else that you would like to include in this document, something of extra importance?

Table 2. The patient's responses to the respective questions in the protocol and values of Kendall's W coefficient of concordance

\begin{tabular}{|c|c|c|}
\hline Question no & Patient's responses & $\begin{array}{l}\text { Value of Kendall's W co- } \\
\text { efficient of concordance }\end{array}$ \\
\hline 1. & $\begin{array}{l}\text { - A Wonderful mother and a wonderful childhood } \\
\text { - Starting one's own family and helping my wife graduate from school } \\
\text { and get a job }\end{array}$ & 0.87 \\
\hline 2. & $\begin{array}{l}\text { - One's family is what always matters most } \\
\text { - Dilemmas about entering into a new relationship and the final deci- } \\
\text { sion to stay within the first one }\end{array}$ & 0.8 \\
\hline 3. & $\begin{array}{l}\text { - The role of a father, the head of the family } \\
\text { - Being successful at work }\end{array}$ & 0.8 \\
\hline 4. & $\begin{array}{l}\text { - Family } \\
\text { - Being appreciated at work (Bronze Cross of Merit) }\end{array}$ & 0.73 \\
\hline 5. & $\begin{array}{l}\text { - A sense of being lonely at present } \\
\text { - Joy of having children and grandchildren }\end{array}$ & 0.8 \\
\hline 6. & $\begin{array}{l}\text { - Warning parents against making mistakes } \\
\text { - Taking good care of one's health } \\
\text { - Caring for the family ties }\end{array}$ & 0.33 \\
\hline 7. & $\begin{array}{l}\text { - Making the most of one's life - reasonably } \\
\text { - Limited trust with regard to all strangers } \\
\text { - Avoiding naivety of approach in life }\end{array}$ & 0.8 \\
\hline 8. & $\begin{array}{l}\text { - Children as life's topmost priority } \\
\text { - Making the most of one's life }\end{array}$ & 0.8 \\
\hline 9. & $\begin{array}{l}\text { - A sense of remorse and a desire to make amends } \\
\text { - A bitter sense of being lonely and abandoned by one's loved ones } \\
\text { - A desire to be noticed and recognized for who one really is }\end{array}$ & 0.3 \\
\hline
\end{tabular}

\section{Results and discussion}

To best show the patient's point of view, the interview was subjected to content analysis. These are presented as quotations below.

Evaluation of the patient's responses to individual questions gives good grounds to believe that by far the greatest emotional significance was attached by him to a family, be that in terms of his own background "I had a wonderful mother, parents... I can still recall my childhood... my mother's and my father's warmth, ... childhood was a wonderful and happy time", as well as his own family - wife and children "I was always very emotionally involved in every single success or 
Table 3. Survey questionnaire intended to evaluate the effects of the therapy, along with the patient's responses

\begin{tabular}{|c|c|}
\hline Dignity therapy — summary & Patient's responses \\
\hline 1. Following the therapy, my mental well-being improved & 5 \\
\hline 2. I hope my family will feel better when they see the recording & 3 \\
\hline $\begin{array}{l}\text { 3. I believe that thanks to this message, my loved ones will see me in a different light, and so } \\
\text { our relationship will improve }\end{array}$ & 3 \\
\hline 4. I feel more at peace now & 5 \\
\hline $\begin{array}{l}\text { 5. I have a sense that some things that truly matter to me have now been spelt out and } \\
\text { named properly }\end{array}$ & 4 \\
\hline $\begin{array}{l}\text { 6. I believe this particular form of communication made it easier for me to get across some } \\
\text { truly important matters, as well as helped me reveal my feelings to my loved ones }\end{array}$ & 5 \\
\hline 7. I feel that thanks to this recording, I have now left an important message for my family & 4 \\
\hline $\begin{array}{l}\text { 8. This method of communication was much easier for me than speaking face to face with } \\
\text { my loved ones }\end{array}$ & 3 \\
\hline 9. I have a sense that I have now done something important both for myself and others & 5 \\
\hline $\begin{array}{l}\text { 10. I believe that thanks to this recording, various difficult matters might well be smoothed } \\
\text { out now }\end{array}$ & 4 \\
\hline
\end{tabular}

Table 4. Arithmetic mean of patient's responses stratified by respective categories

\begin{tabular}{llc} 
Category & $\begin{array}{l}\text { No of } \\
\text { respecti- } \\
\text { ve state- } \\
\text { ments }\end{array}$ & $\begin{array}{c}\text { Arithmetic } \\
\text { mean }\end{array}$ \\
\hline $\begin{array}{l}\text { Benefits for one's own } \\
\text { mental well-being }\end{array}$ & $\begin{array}{l}1,4,5, \\
6,7,9\end{array}$ & 4.67 \\
\hline Benefits for the family & $2,7,9$ & 4 \\
\hline $\begin{array}{l}\text { Hope for improving the re- } \\
\text { lationships with the family }\end{array}$ & $\begin{array}{l}3,6,8,10 \\
9\end{array}$ & 4 \\
\hline
\end{tabular}

failure of my own children..., I always kept the family uppermost in my mind, ... my top priority was their wellbeing, ... my greatest achievement was definitely the family". He was particularly keen on getting in touch with his daughters and grandchildren "I would very much like to see my grandson, granddaughter and children from time to time". He nursed a great grievance to his ex-wife due to numerous instances of her unfaithfulness "The things I managed to forgive my wife - no other man would ever bring himself to do it... We just let our great love perish". He could not understand why his own family had left him in illness, and very much wanted this situation to be reversed "What made you rip me out of your life so drastically...?, I feel so terrible being abandoned and left alone". He apologized for the error of his ways and asked his daughters to get in touch with him "If I did something wrong, and I did a lot of bad things in my life - I'm simply sorry... Please reach out to me, if you can...".
Another topic often referred to by the patient was his work, be that in Poland "While working in a planning and design company I was much appreciated for my output..., I even got awarded a Bronze Cross of Merit, ... I was very resourceful, I could do the things other people could only dream of, ... I had a sense of having found the place I truly belonged to" and abroad "A trip to America, these were also the great plans ... when I brought along a fat bank cheque and laid it on the table next to my sister - I burst into tears then, "see Magda", I said, "my first, hard-earned, real money". He paid particular attention to financial assistance he could extend to his family thanks to his own hard work "Those were pretty large lumps of money, even by American standards, ... I provided for my family, ... I was sending over packages full of goods, as much as I could...".

An equally important issue for the patient was his life's passion - playing the drums and the successes associated with being a professional musician "Out of a self-study amateur I became a professional drummer, as I passed the so-called technical verification, ... the exams were pretty thorough, ... at the time we played at the biggest events in town". Apart from the sheer pleasure he derived from playing the drums, it was also a nice side-earner for him "I started making money as a drummer", as well as very much enhanced his overall social standing and status within his own family "I would take the children to a stage rehearsal, so they could see how things were actually done... how music was being made, ... now and again, I would also take along my wife, so she could socialise there and have some fun." 
The selection of this particular patient was by no means accidental, as not all of the potential candidates would be capable of attending a dignity therapy [6]. The patient was selected in view of his physical condition, family circumstances, and capacity to reflect on, and address the issues of dying.

As regards one's adaptation to the attendant disease circumstances, in line with the literature on the subject [7], this process occurs on the two levels, i.e. dealing with the disease and the accompanying problems, and dealing with life at large, now that its course has been altered in result of the disease. At the first level, it is essential to adapt to the symptoms of the disease and the constraints it brings about, as well as effectively adapt to the hospital setting. At the second level, the importance of one's emotional balance and maintaining good relationships with one's the family and friends is highlighted. If these issues are related to the patient's situation, it is particularly important to allow him to re-establish contact with the family as a remedy in the process of adaptation to the disease.

In matching the conscious behaviour with the patient's individual circumstances, a chance to manage one's life became of particular significance. Considering that both the patient and his family actually stood to achieve tangible benefits from attending the study $[8,9]$, a dignity therapy was suggested to the patient as an option. The intervention was aimed to ameliorate the sense of helplessness when it comes to the relationship with the family. Previously, the patient had neither any concept nor enough courage to attempt getting in touch with his family. Consequently, in this particular case, the dignity therapy was invested with yet another, additional objective, originally unintended by its authors, i.e. recovering the family ties.

The results yielded by the study give rise to the conclusion that the most important benefit derived from attending this dignity therapy was an enhancement of the patient's mental well-being. Assorted family issues and the hope for improving the relationships within the family fold were equally noted.

Interference in the lives of others facilitated through the procedures of dignity therapy raised potentially controversial issues already highlighted by Danish investigators [6]. While the patient willingly consented to attend the therapy, his family was not offered any choice in receiving the resultant recording, whose content might potentially cause distress. The length of time to response from the recipients of the recording may give some grounds to this belief.

Simonton notes that a first-hand experience of cancer diagnosis in a family member may cause deep anxiety within a family, and potentially shunning a direct contact with the victim [10]. It is well-worth highlighting this fact, as when the family saw the patient last, his physical condition was fine, with no symptoms of illness, and so there was not a chance of gradually getting used to the visible changes in his overall condition. Another reason for a communication break that occurred may well be attributed to some as yet non-ameliorated conflicts from the past. It is also worth noting at this juncture, that authors have never been availed of a full picture of the circumstances at issue, as they have been appraised of the version of events furnished by one of the parties only, i.e. the patient himself.

On the other hand, previous studies reveal a significant mood enhancement and appreciably increased hope, even in the case of patients suffering from depression [11]. Authors of this case report could make an assumption of improving an emotional comfort to a patient with no apparent mood disorders and other emotional issues. It might, therefore, be assumed that some tangible, psychological benefits might well be gained, which is corroborated by the data acquired through the survey questionnaire summarizing the effects of the therapeutic procedure.

Attendance in dignity therapy may be regarded as a confrontational activity: on the one hand, the patient confronted his own emotions related to some difficult life issues, while on the other hand, one cannot ignore an indirect, yet by no means less important confrontation of the patient's family with his own take on the circumstances. This fact is of some significance, as Polish study reveals a clear correlation between an active, confrontational style of coping with the disease, and a better adaptation to its constraints [12]. With regard to the patient at issue, such a confrontation was facilitated for him, yielding some unexpected results.

Three months following the dignity therapy procedure, the patient's daughters visited. Following prolonged face to face discussions, an emotional bond was reconstituted. Until his death, both daughters remained in regular touch with their father. successful recovery of family ties was a totally unintentional effect of the patient's attendance in the dignity therapy, thereby significantly increasing its therapeutic value, both for the patient and his family. By far the testimony to the overall effectiveness of the therapy was the patient's statement when his condition had deteriorated. When asked by the psychologist whether he would still like to do something, or whether he had any other wishes, he said that as far as he was concerned, all matters of true importance to him were already settled. The patient died four months after the application of the intervention. 


\section{Conclusions}

This patient experienced a notable improvement in his mental well-being, following his attendance in the dignity therapy session. Access to the recording to the patient's family ultimately resulted in the re-establishment of the family ties, and a significant improvement in the patient's overall comfort. Tackling hard and challenging emotions during the dignity therapy made it possible for the patient to be granted his wish for a reconciliation with his daughters before his death. Not only did it prove effective in terms of enhancing the patient's sense of dignity, but also instrumental in tangibly improving the relationships within a family structure. It would be highly recommendable to pursue more extensive research into the dignity therapy procedure, construed as a therapeutic instrument that boasts an appreciable potential for application in addressing and effectively tackling the relationships within a family fold at large.

\section{References}

1. Horacy. Exegi monumentum aere perennius. Pieśń III. 30.

2. Chochinov HM, Kristjanson $\sqcup$, Breitbart W, et al. Effect of dignity therapy on distress and end-of-life experience in terminally ill patients: a randomised controlled trial. Lancet Oncol. 2011; 12(8): 753-762, doi: 10.1016/\$1470-2045(11)70153-X, indexed in Pubmed: 21741309.

3. www.who.int/cancer/palliative/definition/en/.
4. Mcllfatrick S, Connolly M, Collins R, et al. Evaluating a dignity care intervention for palliative care in the community setting: community nurses' perspectives. J Clin Nurs. 2017; 26(23-24): 4300-4312, doi: 10.1111/jocn.13757, indexed in Pubmed: 28178386.

5. De Walden-Gałuszko K. Wybrane zagadnienia psychoonkologii i psychotanatologii. Uniwersytet Gdański, Gdańsk 1992.

6. Houmann U, Rydahl-Hansen S, Chochinov HM, et al. Testing the feasibility of the Dignity Therapy interview: adaptation for the Danish culture. BMC Palliat Care. 2010; 9: 21, doi: 10.1186/1472-684X-9-21, indexed in Pubmed: 20860786.

7. Borys B, Majkowicz M. (red.). Psychologia w Medycynie (wybrane zagadnienia). Akademia Medyczna w Gdańsku, Gdańsk 2006.

8. Fitchett G, Emanuel L, Handzo G, et al. Care of the human spirit and the role of dignity therapy: a systematic review of dignity therapy research. BMC Palliat Care. 2015; 14: 8, doi: 10.1186/s12904-015-0007-1, indexed in Pubmed: 25844066.

9. Hall S, Edmonds P, Harding R, et al. Assessing the feasibility, acceptability and potential effectiveness of Dignity Therapy for people with advanced cancer referred to a hospital-based palliative care team: Study protocol. BMC Palliat Care. 2009; 8: 5, doi: 10.1186/1472-684X-8-5, indexed in Pubmed: 19445711.

10. Simonton OC, Matthews-Simonton S, Creighton JL. Triumf życia, możesz mieć przewagę nad rakiem. Ravi, Łódź 2005.

11. Vaghee S, Heydari A. The Effect of Dignity Therapy on Hope in Patients with Major Depression Disorder. Global Journal of Health Science. 2016; 8(12): 118, doi: 10.5539/gjhs. v8n12p118.

12. De Walden-Gałuszko K. (red.) Psychoonkologia. Biblioteka Psychiatrii Polskiej, Kraków 2000. 